\title{
Análise 3D das estruturas de bandas de EBG através do método dos elementos finitos.
}

\author{
Vinícius F. Lopes*, Marcos S. Gonçalves.
}

\section{Resumo}

Neste estudo são investigadas as estruturas de bandas eletromagnéticas proibidas implementadas em linhas de transmissão do tipo micro-fita, com foco na região de frequências de micro-ondas. Aspira-se a obtenção de parâmetros fundamentais para o projeto de dispositivos, como permissividade elétrica efetiva, largura das trilhas e frequência central da região proibida. Para a realização das análises, empregou-se o método dos elementos finitos 3D, sendo que somente uma célula de periodicidade de cada estrutura foi utilizada.

\section{Palavras-chave:}

EBG, Microfita, MEF.

\section{Introdução}

As EBGs são estruturas periódicas dielétricas ou metálicas inseridas em material dielétrico de tal modo que, quando dispostas ao longo dos eixos de propagação de uma onda eletromagnética, possuem uma resposta seletiva em frequência, criando-se regiões de banda proibida para esta propagação em uma, duas ou três dimensões.

Embora as análises das estruturas de bandas periódicas sejam comuns em projetos de dispositivos fotônicos, o mesmo não ocorre na região de micro-ondas, cujas aplicações inspiram a realização deste trabalho. A metodologia utilizada permite determinar as bandas em mais de uma direção e a permissividade elétrica efetiva do meio.

\section{Resultados e Discussão}

Como mencionado anteriormente, as análises das estruturas de bandas das EBGs foram realizadas pelo método dos elementos finitos 3D para problemas de autovalores [1]. Foram investigados três tipos de célula de periodicidade implementadas em microfita. No primeiro, não foram introduzidas perturbações que causassem alteração significativa da permissividade elétrica nas camadas da estrutura, para que se obtivesse um parâmetro de comparação do comportamento do campo elétrico.

No segundo tipo, introduziram-se perfurações cilíndricas de raio $1,27 \mathrm{~mm}$ no plano terra, criando-se um padrão de geometria como o da figura 1 . Foram examinados dois cenários distintos. Inicialmente, para uma largura de $0,686 \mathrm{~mm}$ da trilha condutora, considerou-se uma constante dielétrica de 10,5 do substrato com espessura de $0,635 \mathrm{~mm}$, obtendo-se um band gap em torno da frequência de $11 \mathrm{GHz}$ [2]. Em seguida, para uma largura de $0,470 \mathrm{~mm}$ da trilha condutora, considerou-se um substrato de constante dielétrica igual a 3,55 e espessura de $0,203 \mathrm{~mm}$, obtendo-se um band gap em torno de 16 $\mathrm{GHz}$, como se pode ver na figura 2 .

Por fim, no terceiro tipo, a largura da trilha condutora foi alterada ao longo da estrutura, de modo que sua impedância característica variasse. Esta análise introduziu a possibilidade de geração de band gaps por stubs adicionados à trilha, de modo análogo a estruturas EBGs com anéis capacitivos.

As células de periodicidade do terceiro tipo também foram analisadas em dois cenários distintos, sendo que no primeiro deles a impedância característica da trilha condutora variou (por alteração de sua largura) de 31 ohms para 80 ohms, enquanto no segundo caso esta variação ocorreu de 25 ohms para 100 ohms [3].
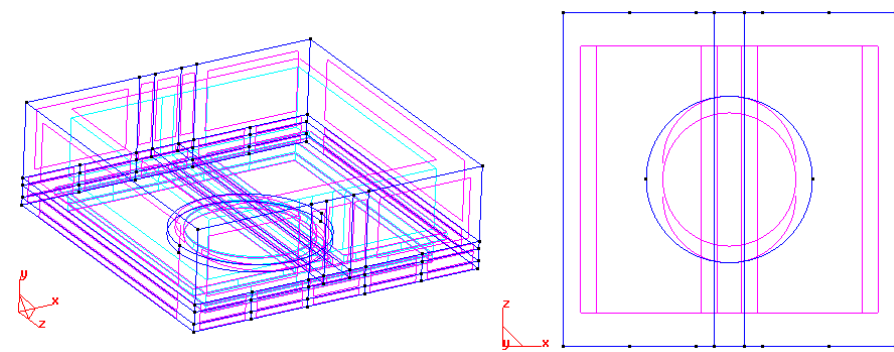

Figura 1. Vistas ortogonal e superior da geometria com periodicidade no plano terra, criada utilizando-se o software GiD.
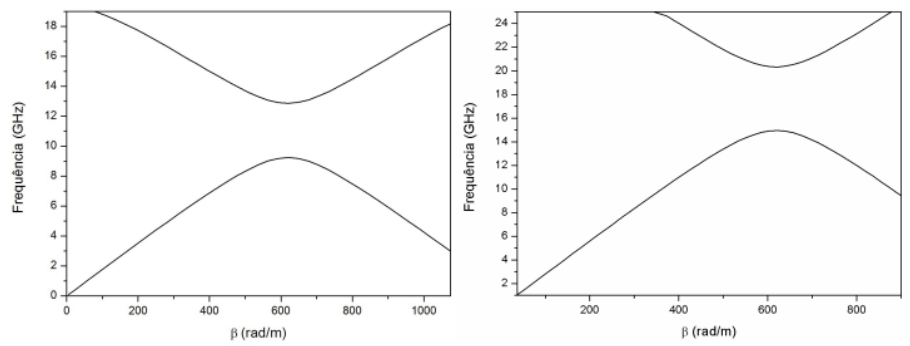

Figura 2. À esquerda, band gap gerado pela estrutura com periodicidade no plano terra e constante dielétrica 10,5. À direita, band gap gerado pela estrutura com periodicidade no plano terra e constante dielétrica 3,55.

\section{Conclusões}

Os resultados obtidos indicam que diferentes formas de periodicidade geram band gaps adequados para diferentes aplicações. Além disso, tratando-se de estruturas com periodicidade na trilha condutora, quanto maior a diferença entre as impedâncias características dos trechos, maior será o band gap gerado.

\section{Agradecimentos}

Agradeço ao meu professor e orientador Marcos S. Gonçalves pelo suporte e paciência ao longo da elaboração deste projeto e à CNPq por investir e incentivar a execução de pesquisas como esta.

\footnotetext{
${ }^{1}$ Gonçalves, M. S.; Isayama, Y. H. e Figueroa, H. E. H. A novel three dimensional vector finite element method for periodic photonic devices. 2016, vol. 58 , no. 11.

2 Rasdisic, V.; Qian, Y.; Coccioli, R. e Itoh, T. IEEE Microwave and Guided Wave Letters. 1998, vol. 8, no. 2.

${ }^{3}$ Nesic, D. e Nesic, A. Microwave and Optical Technology Letters. 2001, vol. 29 , no. 6 .
} 